\begin{tabular}{|c|c|c|}
\hline $\begin{array}{l}\text { PKS } \\
\text { PUBLC } \\
\text { KNOWLDGE } \\
\text { PROJECT }\end{array}$ & $\begin{array}{c}\text { REVISTA DE GEOGRAFIA } \\
\text { (RECIFE) } \\
\text { http://www.revista.ufpe.br/revistageografia }\end{array}$ & 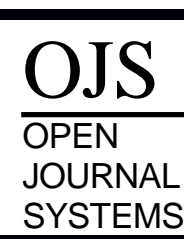 \\
\hline
\end{tabular}

\title{
NO ITINERÁRIO DOS EXPULSOS PELA UHE ESTREITO. TERRITÓRIO DOS SUJEITOS RIBEIRINHOS NO RIO TOCANTINS
}

\author{
Elizeu Pereira de Brito' ${ }^{1}$ Maria Geralda de Almeida ${ }^{2}$
}

\author{
${ }^{1}$ Professor Adjunto do Curso de Geografia da Universidade Federal do Tocantins - Campus de Araguaína. \\ Email: eliseubrito@uft.edu.br \\ ${ }^{2}$ Professora colaboradora da Universidade Federal de Sergipe. Email: mgdealmeida@gmail.com
}

Artigo recebido em 22/02/2017 e aceito em 17/08/2017

\begin{abstract}
RESUMO
A pesquisa foi realizada com ribeirinhos das margens do rio Tocantins no percurso Barra do Ouro - Tocantins à Estreito - Maranhão. Trata-se de uma pesquisa realizada em dois momentos, com o ribeirinho na margem do rio Tocantins e os mesmos, "expulsos" do território pós enchimento do lago da UHE Estreito. Desenvolvemos a pesquisa com entrevistas semiestruturadas e pela observação com participação na comunidade. $\mathrm{O}$ avanço do agronegócio no Cerrado tocantinense se intensificou nos anos 2000, período que coincide com o início das construções, no Estado, de hidrelétricas no rio Tocantins, que já totalizam quatro usinas em funcionamento: a UHE Estreito, a UHE Luís Eduardo Magalhães - Lajeado -, a UHE São Salvador e a UHE Peixe-Angical. Os lagos daí resultantes submergiram os territórios dos ribeirinhos, sujeitos tocantinenses e maranhenses ou migrantes de outros estados. $\mathrm{O}$ entendimento do território fundamenta-se em Jöel Bonnemaison para quem o território tem função social e cultural. Nesta leitura foi possível delimitarmos entre identificação e territorialidades algumas faces da vivência dos ribeirinhos do rio Tocantins. Entre territórios e desterritorialização há uma reterritorialização dos sujeitos em ambientes diferentes aos seus territórios ribeirinhos.
\end{abstract}

Palavras-chave: Produção de Alimentos; Construção de Hidrelétricas; Desterritorialização, Ribeirinhos.

\section{THE ITINERARY OF THE EXPULSOS BY UHE ESTREITO. TERRITORY OF SUBJECTS RESIDENT OF THE MARGINS OF RIVER TOCANTINS}

\begin{abstract}
The research was made with residents of margins of the Tocantins river in Barra do Ouro - Tocantins up until Estreito - Maranhão. This is a research carried out in two stages, with the residents of margins of the river in the Tocantins river and the same, expelled from the territory of filling the post of UHE Estreito lake. We develop research on semi-structured interviews and the observation with community participation. The advance of agribusiness in Tocantinense Cerrado intensified in the 2000s, a period that coincides with the start of construction in the state of dams on the Tocantins river, which now total four plants in operation: the UHE Estreito, UHE Luís Eduardo Magalhães - Lajeado - the UHE São Salvador and HPP Peixe-Angical. The location of the lakes resulting submerged the territories of the riveri, Tocantins and Maranhão subject or migrants from other states. The territory of understanding be based on a reading Jöel Bonnemaison regarding its understanding that the territory has social and cultural function. This reading was possible to circumscribe between identification and territoriality faces some of the experience of the basin of the Tocantins River. Between territories and dispossession there is a repossession of subjects in different environments sujects residents of margins the rivers territories.
\end{abstract}

Key-words: Food Production; Construction Hydroelectric; Deterritorialization; Fishermen. 


\section{INTRODUÇÃO}

As margens do rio Tocantins foram ocupadas por vaqueiros vindo principalmente dos Estados do Maranhão e Piauí no século XIX. A expansão do gado na Região de Pastos Bons no Maranhão só foi possível após a ultrapassagem do rio Parnaíba que se apresentava como uma barreira. Não apenas o fato do rio apresentar obstáculos, mas os índios Timbiras habitantes dessa região eram considerados como um dos maiores problemas para a ocupação e permanência dos fazendeiros (CABRAL, 1992). Com a diminuição das caças, os índios Timbiras passaram a abater o gado. Isso foi um dos fatores que implicaram na matança de indígenas para desocupar o espaço para a pecuária. Esta ocupação chegou até o rio Tocantins e os fazendeiros principiaram a ocupar as terras do norte do Tocantins, principalmente as margens do rio Tocantins aproveitando as várzeas fertilizadas pelas cheias do rio.

A rota do rio Tocantins foi a principal via de circulação da população do Norte de Goiás, hoje Tocantins, até as décadas de 1960. Esta era movimentada por barcos que levavam e traziam produtos da cidade de Belém, capital do Pará. O meio de transporte fluvial perdeu força com a abertura da rodovia Belém-Brasília. Esta desintegrou o sistema, mas o transporte de curta distância ainda permaneceu por longo tempo tendo o rio Tocantins como principal via de transporte. As redes rodoviárias integrando as cidades e comunidades rurais a rodovia foram, sem dúvida, o momento de rompimento da navegação comercial no rio Tocantins.

No entanto, os ribeirinhos continuaram a depender do rio para se locomover. Em muitos lugares, como nas ilhas, somente o transporte fluvial era possível. Para estes, mesmo possuindo automóveis para se locomover ainda utilizam o barco como meio de transporte porque é uma locomoção acessível. Neste olhar, convém analisar conflitos quando há esta ruptura do ribeirinho com o rio Tocantins. Para isso, tomamos como lócus de observação as comunidades ribeirinhas atingidas pelo Lago da Usina Hidrelétrica Estreito - UHE Estreito.

O processo de expulsão dos ribeirinhos da margem do médio rio Tocantins e os efeitos disso na oferta de alimentos produzidos no Cerrado no norte do Tocantins pós-construção da UHE Estreito incitou-nos a pensar a problemática e ter respostas aos questionamentos: como se estabelecia a interdependência dos sujeitos com o rio Tocantins? Que territorialidades estavam construídas antes e após a construção da Usina Hidrelétrica Estreito - UHE Estreito. Qual a importância dos ribeirinhos para a região na produção de alimentos?

Do período que convivemos com os atingidos pela barragem fizemos uma observação empírica e entrevistas com sujeitos ribeirinhos. Com um olhar geográfico sobre o objeto, por 
meio de uma relação entre o estudo que desenvolvemos com ribeirinhos e a discussão tematizada sobre o Cerrado tocantinense. Desta maneira, foi possível analisar algumas questões pertinentes ao processo que não é novo, e é somente mais uma forma de expropriação dos povos do Cerrado ${ }^{1}$ pelos grupos capitalistas.

A relação do ribeirinho com rio Tocantins era de afeto e de dependência. Dependia da pesca, da coleta de frutos e da fertilidade do solo para sobreviver. Também, o rio era seu principal meio de transporte, por meio do qual o ribeirinho levava o excedente de sua produção para vender nas cidades mais próximas como nas feiras de Estreito-MA e Babaçulândia-TO. Em compensação, nelas o ribeirinho comprava ferramentas e mercadorias que não era possível produzir em sua terra, pela improdutividade do solo, pelo regime hídrico e as cheias do rio Tocantins ou mesmo, por não terem tecnologias para tais produções.

Utilizando de entrevistas para identificar os itinerários dos sujeitos vitimizados por este processo, constatamos que estes indivíduos são expropriados, ou filhos de expropriados da terra pela seca ou pela grilagem da terra. Em sua maioria, estes sujeitos são filhos de migrantes do início do século XX ou migrantes expropriados da terra no Maranhão e no Piauí dos anos 1940/1950. Os fatores de retiradas são diversos, inclusive até em decorrência das secas, como no relato abaixo, citado por Sá e Brito.

'Uma viage pra cá garimpá' traz à tona lembranças de um passado marcado pela seca do Nordeste na década de 1940, motivo pelo qual trouxe o menino Custódio e sua família para Estado do Tocantins, sem saber se o menino estava participando de uma migração fixa e que nunca mais voltaria ao lugar deixado (SÁ; BRITO, 2012, p. 160).

Por outro lado, os sujeitos dos lugares recordavam das políticas públicas com uma lembrança pessimista, um motor que impulsionou o ciclo de grilagem de terra. Sem terra e sem o Estado brasileiro que os apoiassem, a saída foram eles se esconderem nas barrancas do rio Tocantins, território para alguns sagrado, até que as águas chegassem em suas terras e iniciassem uma migração, ou mais uma migração rumo à Terra do Bem Virá - Pará.

\footnotetext{
1 Referimo-nos a povo do Cerrado na perspectiva da discussão em que Valney Dias Rigonato vem desenvolvendo em sua tese sobre os sujeitos que habitam este bioma brasileiro numa leitura cultural. Disponível em: https://repositorio.bc.ufg.br/tede/bitstream/tede/7591/5/Tese\%20\%20Valney\%20Dias\%20Rigonato\%20-\%202017.pdf..
} 


\section{POR UM ENTENDIMENTO DO TERRITÓRIO}

A categoria que utilizamos para a construção da leitura geográfica sobre os ribeirinhos foi o território, fundamentado, principalmente, em Bonnemaison (1987). Este autor discute o território enquanto uma rede articulada de lugares e itinerários, e os indivíduos têm o território muito mais como um espaço de identificação do que de apropriação.

Ao fazer uma leitura da ilha de Tanna na Oceania, o autor concluiu que a perca do território para determinadas etnias pode representar a "morte". Há um vínculo muito forte entre os grupos e seu território. Ainda para o autor, a desterritorialização é apresentada como uma expulsão ou perda da identificação com o território pelos indivíduos.

Na compreensão de Haesbaerth (2005), a desterritorialização seria o deslocar o sujeito do território. Para tanto, o autor expõe que nesta perspectiva ela é um mito, ou seja, fala-se muito em área de conflitos ao processo de desterritorialização, quando o sujeito que se encontra ali, ele é levado para fora do seu território. Ao ser levado, arrancado, expulso, haveria uma desterritorialização do sujeito e, não do território.

Neste norteamento, partimos do pressuposto que houve desterritorialização dos sujeitos ribeirinhos. Também, há a considerar as territorialidades entendidas como as estratégias que permitem ao indivíduo fazer parte do território. São estratégias políticas, de pertencimentos, das relações afetivas ou parafraseando Bonnemaison (1987), são relações simbólicas míticas. As territorialidades também são relações, ou seja, só se pode estabelecer territorialidades com um dado território quando há uma relação afetiva ou estratégia de sobrevivência, ou de interdependência conforme Bonnemaison (1993). Daí, por meio dos objetos produzidos pelo homem ou naturais, este autor (1987) afirma ser o território enquanto uma relação social e cultural de sujeitos com a terra.

\section{VIDAS RIBEIRINHAS}

Nos relatos de algumas expedições que passaram em meados do século XIX pelo rio Tocantins como a de Rufino Segurado, descreve-se que população do norte do Tocantins era constituída por "povos preguiçosos", que nem conseguiam trabalhar. Porém, o tempo de um relógio, da racionalidade econômica europeia, não rege o tempo que um ribeirinho aprendeu a lidar no manejo com o rio. Para ele, o rio é quem determina a hora de plantar, de colher, de pescar e a hora de descansar. Os homens ribeirinhos são sujeitos que vivem às margens dos 
rios e dependem do ciclo de cheia e seca para plantar. Ciclo bem definido na porção norte do Tocantins, com um período chuvoso e outro de estiagem, cada um perdurando seis meses.

Rigorosidade climática que o ribeirinho conhecia bem. O rio é a principal fonte de água e de alimento para esses sujeitos que apreenderam a conviver com a natureza e suas variações anuais. Aprendem na convivência cotidiana com a baixa e a subida das águas, com a alteração da cor das águas que indicam o momento do plantio ou mesmo de sair ou voltar para casa. O deslocar das pessoas dependia da intensidade das chuvas, que ditavam o nível das águas do rio Tocantins. Quando os primeiros raios do sol refletiam sobre o rio Tocantins, os ribeirinhos dirigiam-se até as margens do rio, para um ritual de lavar o rosto toda manhã observar o movimento dos cardumes pela diferenciação na correnteza das águas, ou mesmo fazer uma reza sagrada para reverenciar o rio ou a água. E a lida com a água começava com o embarque de caixas, cordas e pessoas e, os barcos que partiam movimentando a vida nos lugares. Levavam foice, enxada, grãos ou animais e o excedente da colheita para vender na cidade, bem como crianças para estudar ou professoras para ensinar nos assentamentos. No entardecer era preciso retornar-se ao rio para banhar e buscar renovação das energias.

Para Bonnemaison (2002) como já foi dito, o território tem função social, mas também tem função cultural. O simbólico é representado por uma rede de lugares sagrados, denominados por este autor de "lugares fundador". Fazendo um estudo profundo dos originários da Ilha de Vanuatu, Bonnemaison comenta que estes são lugares de primeira aparição, de realizações de danças que determinam ser ali o lugar do início da existência da pirogue. A pirogue é uma metáfora que o autor recorre para denominar as comunidades territorializadas. Uma alusão a migração e identificação com o território pelos vanuatenses. Esta rede de lugares que formam este território é pontilhada por lugares singulares, denominados de geossímbolos (BONNEMAISON, 1987).

Com base na leitura dos geossímbolos pode se afirmar que o rio Tocantins é um lugar simbólico. O rio para as crianças é/era local de brincadeira. Porém, tal como mencionou Araújo (2009, p. 39): "para o adulto ele assume outras representações, porque com o passar do tempo ele se transforma, se configura em lugar de trabalho, de lidas cotidianas, onde busca prover as necessidades e o sustento da família". O rio dita as regras naturais, para seu uso e de suas planícies, que as crianças apreendem no convívio familiar. É preciso saber plantar nas terras alagadas é outro planejamento, diferente do plantio em terra firme. A roça precisa ser inventada todo ano. Necessário é saber plantar no lameiro, sem errar o tempo cronológico mas, principalmente, o tempo das águas, pois nem todos períodos chuvosos e secos são iguais. 
Isso exige, pois, muita atenção para os sinais que a natureza emite. A terra deixada pelas cheias do rio determina o que se pode plantar: de sementes de melancia e de abóbora a do feijão, tudo é uma questão da fertilidade propiciada pelos sedimentos deixados pelo rio, indicando o melhor para o plantio, sinais que o ribeirinho conhece muito bem.

A relação das comunidades tradicionais com o rio Tocantins se dava pela dependência do viver. As áreas férteis no entorno do rio eram bem diferentes da imensidão dos solos pobres nos chapadões do cerrado. Para estas comunidades estas eram áreas que não produzem o suficiente para garantir a alimentação e a venda do excedente da produção com as técnicas de plantio que lhes estavam disponíveis.

Nas safras havia fartura de alimentos nas cidades. Os barcos traziam o feijão, o milho verde, o porco, a galinha caipira e o mel entre outros. As pequenas cidades tornavam-se praças de vendas de produtos agrícolas ou de frutos colhidos das margens do rio, tais como o buriti e o murici. No vale do rio Tocantins, as comunidades camponesas que viviam ali há décadas, na maioria de migrantes nordestinos, eram organizadas em associações e cooperativas. O rompimento desta organização se deu com a construção da hidrelétrica Estreito, a quinta UHE construída no rio Tocantins.

Estes ribeirinhos tinham algo em comum, uma interdependência do rio Tocantins. Como afirmou Bonnemaison (1993), o homem imprime suas marcas na paisagem e passa a ser elemento fundamental nela. O próprio território são marcas no solo impregnadas pelas relações sociais. Não é o homem fora da natureza, e Bonnemaison (1987) releva isso principalmente em seus aprofundados estudos sobre Madagascar e na Ilha de Tanna.

Em uma comparação com outros sujeitos no Tocantins que estabeleceram uma interdependência com a natureza, destaca-se a relação de sobrevivência na Região do Jalapão situado no leste do Estado do Tocantins na qual muitos dependiam do esgotamento das áreas de veredas para construir suas roças, chamadas de 'roças de esgoto' pela comunidade local. $\mathrm{O}$ jalapoeiro construiu sua sobrevivência utilizando as terras mais férteis, uma vez que predomina no Jalapão solos pobres em nutrientes, arenosos. Utilizar as veredas foi uma adaptação desses sujeitos para sua sobrevivência. O conhecer e adaptar-se as estações era fundamental para os jalapoeiros como para os ribeirinhos. No caso dos ribeirinhos, desconhecer ou ignorar qualquer sinal do rio era comprometer toda a produção. 
Figura 01: Mapa do lago da UHE Estreito no Tocantins.

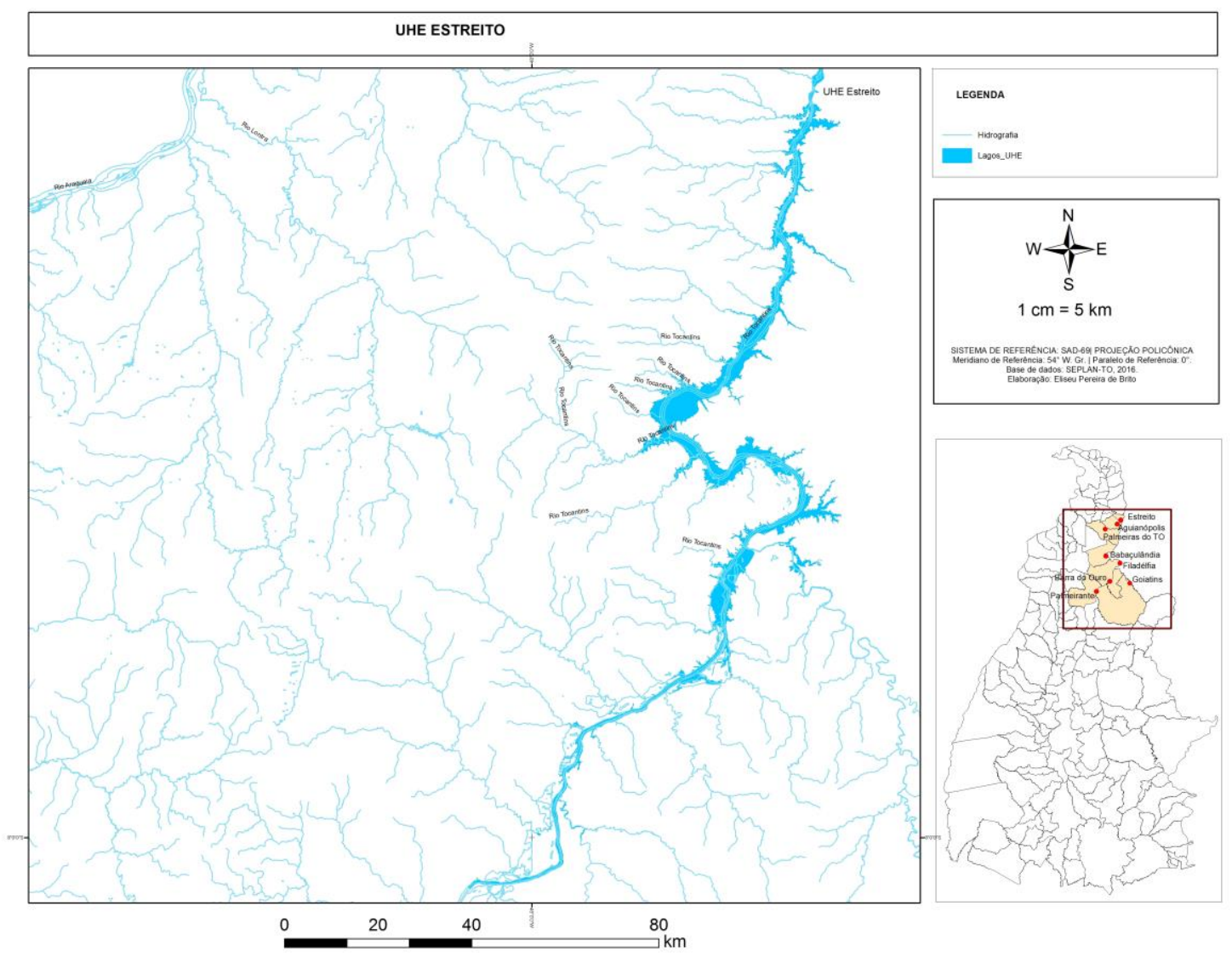

Organizador: Eliseu Pereira de Brito, 2016.

\section{A ROTA RIO TOCANTINS}

Os limites estabelecidos para ser o estado do Tocantins em sua criação em 1988 seguem os contornos dos elementos naturais. Ao norte, os rios Tocantins e Araguaia com seus meandros e canais retilíneos desenham um bico, conhecido como Bico do Papagaio. Com corredeiras, cachoeiras, eles se alargam - estreitam-se, deslumbram olhares e definem vivências em suas ribanceiras. As corredeiras de Santa Isabel no rio Araguaia ou as corredeiras do Funil ou a cachoeira de Santo Antonio no rio Tocantins, entrecruzam nas narrativas dos viajantes e, em sua maioria, causava pavor. $\mathrm{O}$ maior medo dos navegantes era a chegada e passagem por estes lugares.

Sempre os primeiros obstáculos da navegação no rio Tocantins eram as corredeiras do Lajeado. Esta corredeira de 200 metros de largura era temida pelo viajante devido aos redemoinhos que fazem nas águas com o relevo encaixado entre a serra do Lajeado e a do Estrondo. Hoje, na ponte Imigrantes Nordestinos Padre Cicero é possível ver o afunilamento 
do rio e os afloramentos de rochas temidos pelos viajantes. Na altura da cidade de Estreito o rio Tocantins se afunila, formando um canal considerado um do mais estreito do rio Tocantins. Neste local foram feitas a ponte da ferrovia Norte-Sul, da rodovia Belém-Brasília e a UHE Estreito a três quilômetros do estreito do rio Tocantins.

Pelas águas desse rio o comércio se dinamizou. As alterações nos fluxos de mercadorias, como o sal e o querosene foram de impactos significativos. Também, possibilitou exportar a produção como o látex da mangaba e a mão de obra para a colheita de castanha do Pará nas regiões de Marabá (BRITO, 2009).

O rio Tocantins nasce na Lagoa Feia, no Parque de Águas Emendadas no Distrito Federal em altitude em torno de $1.000 \mathrm{~m}$. Seu maior desnível é enquanto rio Maranhão, depois ele será distribuído na maior parte do canal de forma suave. Mas, as suas águas e a composição geológica do leito oferecem obstáculos. O rio Tocantins tem um trecho em torno de 120 km denominado de rio Maranhão e no encontro com o rio Paranã próximo a cidade de Paranã, este passa a ser chamado rio Tocantins. Dali até Esperantina-TO são aproximadamente $1.140 \mathrm{~km}$. Encaixado em depressões, percorre planaltos dentre eles o Planalto Residual do Tocantins, a Serra do Estrondo e a Serra das Cordilheiras.

A navegação do rio Tocantins para alguns autores foi considerada como mais organizada do que a do rio Araguaia. A do Tocantins serviu aos garimpos, interligada aos rios Manoel Alves da Natividade que utilizou-se para o transporte de mantimentos e do ouro e os rios Paranã e Palmas que drenam toda a área do Sudeste do Tocantins, importantes vias de circulação para o período Colonial e, principalmente, para o dito transporte do ouro.

Sua navegação permaneceu até tempos recentes. A rota saindo de Barra do Ouro - TO para Estreito - MA continuou até os anos 2000. Por ali circulavam barcos com sujeitos a negócio, comerciantes transportando mercadorias para vender nas feiras das cidades ribeirinhas, como Filadélfia-TO, Carolina-MA, Estreito-MA e Babaçulândia-TO. Era o ir e vir pelas águas do rio Tocantins que movimentava a vida em suas barrancas. Mas, para os sujeitos acostumados com as enchentes, uma enchente permanente lhes tirou das margens do rio Tocantins sem direito ao retorno: o lago da UHE Estreito.

\section{PELAS ÁGUAS DA UHE ESTREITO}

A Usina Hidrelétrica Estreito foi inaugurada no ano de 2010, concretizando mais um projeto do Governo Federal de construção de hidrelétricas no rio Tocantins. O Consórcio 
Estreito Energia - Ceste - é composto pela Suez Energy International - EUA (40,07\%), Vale BR (30\%), Alcoa - BR (25,49\%) e Camargo Corrêa Energia - BR $(4,44 \%)$ (TRACTEBEL ENERGIA, 2012). Devido aos vários problemas ambientais apresentados na construção da usina e na falta de uma negociação com os ribeirinhos, houve vários embargos à obra com paralização. No entanto, um grupo de parlamentares ligado ao agronegócio no Cerrado entrou com pedido de adiantamento das audiências e conseguiram aprovar requerimentos para garantir a representação da coalizão favorável à obra (CAMARGO e HASHIZUME, 2008).

$\mathrm{Na}$ escala local, houve uma propagação de informações por parte de políticos e empresários locais quanto à importância da obra na geração de emprego e no desenvolvimento local, principalmente articulado com um discurso da soberania energética para alavancar uma industrialização da região. Tais discursos surgem rapidamente para blindar a política contrária à construção de barragem e na rapidez que eles surgem, desaparecem, após deixar uma esperança para a população, mas sem a concretização de tais benefícios. Mas, essas hidrelétricas atendem à política energética do país, principalmente às necessidades das empresas de ferro e alumínio. Há que se frisar, também, que esta construção faz parte da agenda de grupos tocantinense, maranhense e baianos, ligados ao agronegócio no Cerrado. Como apontou Campos Filho (2010), serve para abrir um caminho pelas águas para as toneladas de soja serem exportadas pelo porto de Conde, uma vez que o lago da hidrelétrica rompe um dos empecilhos naturais, as corredeiras do Médio Tocantins.

\section{OS EXPULSOS DO TERRITÓRIO}

Os sujeitos que foram removidos de seu território são chamados de atingidos por barragem. Para Foschiera (2009), há vários conceitos de atingidos, usados como melhor convém à empresa ligada ao setor energético. Uns são ligados exclusivamente à propriedade privada da terra, visando a regulamentação para o pagamento das indenizações. Neste sentido, é interessante ressaltar que o foco é econômico e não vinculam as questões sociais ou psicológicas do processo. Um dos conceitos que tem uma abrangência mais geral é o entendimento do Movimento dos Atingidos por Barragens - MAB, apresentado no trecho a seguir:

O MAB passa a ter a compreensão de que não são apenas os moradores que se localizam na barranca dos rios onde são construídas as Usinas Hidrelétricas que sofrem os impactos negativos causados pela nova política energética, mas toda a população que se vê obrigada a pagar um elevado preço de energia para sustentar os 
altos lucros dos investidores, que se apropriam dos recursos naturais do país e comprometem a própria soberania nacional (FOSCHIERA, 2009, p. 38).

Com este entendimento, a abrangência das obrigações das empresas são maiores e as lutas não têm apenas a questão das indenizações justas, mas também da energia por um custo menor e até uma ampliação dos atendidos pela eletrificação. A participação do MAB nas comunidades dos atingidos pela UHE Estreito foi muito tensa; isso se deve à imagem que a empresa, funcionários públicos e lideranças locais construíram do movimento, como um empecilho para as negociações.

A falta de articulação do MAB no processo de negociação gerou as indenizações individuais, que teve no pagamento em dinheiro ou carta de crédito sua base. Este tipo de negociação foi melhor para o empreendedor, posto que os indenizados compravam onde quisessem seu novo imóvel, tirando, deste modo, o dever de o Ceste criar áreas com infraestrutura. Sem dúvida, pessoas agregadas é problema para o empreendedor, pois se elas se articulam em torno de um objetivo comum, neste caso, na busca pela qualidade de vida, a cobrança pelos direitos torna-se maior.

A criação do Lago da UHE provocou a interrupção das sociabilidades ribeirinhas como a produção por ajuda de mutirão. A navegação de embarcações de pequeno porte foi interrompida, seus principais beneficiários lá não moram mais deslocados para áreas mais seca, fora das margens do rio. De fato, o enchimento do lago possibilitou a expulsão desses sujeitos ribeirinhos de seu território.

Sieben (2012) ressalta que famílias foram reassentadas uma distante da outra, o que dificultou sua articulação para reivindicar seus direitos. Muitos vazanteiros receberam míseros valores, outros nem foram indenizados, casos dos barraqueiros e pescadores. No período em que entrevistamos as populações ribeirinhas nos assentamentos rurais, e ao perguntarmos se as indenizações foram justa, um dos moradores nos respondeu com as seguintes palavras: "Sair do lugar da gente, onde nasci e criei não tem preço" (Senhor Manuel, 2016). Em outras entrevistas, os filhos nos relataram as perdas de um dos familiares quando foi tirado(a) das margens do rio, "meu pai, professor, quando viu aquele aguaceiro inundando suas terras, morreu" (Professora Rita, 2012).

Gomes (2008, p. 360) afirma que o impacto do capital no campo desorganizou a vida unofamiliar campesina e produziu uma expulsão do homem do campo, transformando-o em itinerante-peregrino, boia-fria, que vive nos acampamentos, nas beiras das estradas, e que termina sua peregrinação nas periferias das cidades grandes e médias, como trabalhador 
braçal. "Nelas, na maioria das vezes, passa a viver como marginalizado social, na condição de subempregado ou de assalariado urbano ou de desempregado". Reserva de mão de obra para controle do valor força de trabalho na cidade. Apesar de Gomes (2008) está se referindo ao avanço da fronteira agrícola, isto se aplica à análise em questão quando entendemos que as UHEs no Tocantins são parte da política de ocupação agro mineral (mineral pelo investimento e especulação na extração de ferro e fosfato) no cerrado tocantinense.

\section{DOS ASSENTAMENTOS À FEIRA DE BABAÇULÂNDIA E DE ARAGUAÍNA}

A infertilidade dos solos do Cerrado nos poucos assentamentos construídos para acolher os ribeirinhos mudou drasticamente a forma de lidar com a terra. Para os homens adaptados ao regime do rio no uso das férteis margens do rio Tocantins, na coleta dos frutos e na pesca, adaptar a um novo regime pluvial, que não estavam acostumados a observar, ou mesmo à hora do caminhão pipa, que passa para distribuir água, coloca-se como um desafio. Como afirmou um morador se referindo sobre a sua vida pretérita: "não tínhamos muitas técnicas, mais era o que sabíamos fazer de melhor” (Senhor Sebastião, 2013).

No assentamento Baixão, composto por mais de vinte famílias, em sua maioria proveniente da Ilha de São José ${ }^{2}$ e demais áreas do entorno do rio Tocantins, a água era imprópria para o consumo, por ser salobra. "Não é possível lavar as roupas com ela, o sabão não faz espuma" (Senhora Maria José, 2013), queixou-se uma assentada. Os animais não conseguem bebê-la, apenas a cheiram e rejeitam. Há relatos de moradores que quando chegaram às suas novas propriedades, a maioria de 8 hectares, desconhecendo as propriedades da água, a deram para os animais beberem. Os que beberam, morreram. As torneiras do poço artesianos instaladas para a comunidade, enquanto o visitávamos poucas funcionavam, pois, a maioria estava com problema de entupimento. Também, outro problema era a água imprópria para qualquer uso pois a que saia na torneira, tinha muito sal.

Esses fatores não impossibilitam o plantio, uma vez que as águas pluviais são as determinantes do vigor das lavouras. Mas faltava assistência técnica às famílias nos assentamentos Baixão, Santo Estevão e Itapuã no município de Babaçulândia-TO quanto a nova forma de plantar em solos desconhecidos. Segundo Sieben (2012), das vinte e sete famílias de Palmatuba (município de Babaçulândia), vinte e duas foram para a cidade e, destas, quinze para a cidade de Araguaína, ao passo que apenas cinco foram reassentadas na

\footnotetext{
${ }^{2}$ Ilha de São José era uma das principais ilhas no rio Tocantins, muito utilizada para plantação de alimentos.
} 
zona rural. Um dos fatores que o autor argumentou foi a negociação sem interferência do MAB, com indenização sem uma preocupação de reintroduzir tais famílias em outro local. Assim, os investidores pagaram apenas o preço da terra sem contemplar o ônus da expropriação do campesino, ações que poderiam amenizar, desta forma, o impacto social, emocional e de rearranjo da sobrevivência.

Os ribeirinhos, principalmente de Palmatuba, que tiveram uma parte de suas terras não submersas pelas águas, mesmo morando na cidade sonham em um dia poder voltar à terra. É como se o vínculo com ela não tivesse sido desfeito. Em um estudo feito por Sá e Brito, mostra que eles continuaram a sobreviver do "pedaço de terra" que restou próximo ou distante do rio Tocantins e reclamam da fertilidade do solo:

João Rodrigues é um ribeirinho que viveu parte de sua vida na beira do rio até a sua saída 'forçada' rumo à cidade, e ao ver sua terra coberta por água, ele reclama da distância que ficou para atravessar o rio e ir de encontro à parte da terra que sobreviveu ao alagamento. Para ele a vida na cidade não lhe dá condições de sobrevivência, pois da roça tirava o seu sustento, o 'pedacinho' de terra que lhe restou não é agriculturável e também ficou muito longe da nova moradia (SÁ e BRITO, 2012, p. 165).

A expulsão dos ribeirinhos produziu uma queda na produção de alimentos, detectada nas cidades do norte do Tocantins. Os assentados não conseguem produzir o suficiente para suprir a alimentação da família e vender nas feiras. Com isso houve o rompimento de culturas de várzeas de décadas nas margens do rio Tocantins desorganizando as economias citadinas do entorno. Conforme dados do Instituto Brasileiro de Geografia e Estatística - IBGE -, houve uma redução de mais de quatrocentos toneladas de arroz e quarenta e oito toneladas de feijão no período entre 2008 e 2016 no município de Babaçulândia. Os dados representam uma queda considerável na produção agrícola do referido município, proveniente principalmente pela extinção da produção de alimentos gerada pelas comunidades ribeirinhas.

A feira de Babaçulândia era movimentada nos finais de semana, e ali chegavam os peixes, as verduras e os frutos colhidos pelos ribeirinhos. Em Araguaína, cidade a sessenta quilômetros de Babaçulândia, eram vendidos o peixe e os frutos, principalmente o Murici e o Buriti provenientes dessas comunidades. Em Babaçulândia, a feira não tem mais a importância de antigamente, e uma das causas, apontada pelos moradores, é a falta de produtos, uma vez que quem abastecia a feira eram os ribeirinhos.

No novo galpão da feira de Babaçulândia, os produtos agrícolas vendidos são aqueles industrializados, colocados em sacos de plástico para imitar os da colheita. A falência da feira 
reflete também no papel que o meio rural do município passou a exercer, antes fornecedor de produtos agrícola, agora comprador destes produtos. $\mathrm{O}$ arroz e o feijão são comprados em Araguaína, cidade que exerce o papel de nó na rede urbana regional. Moraes (2008, p. 69) afirma que a produção de alimentos está cada vez mais nas mãos de poucas empresas que dominam as cadeias produtivas do chamado agribusiness, ou seja, as empresas transnacionais que controlam o comércio nacional e internacional de cereais, sementes e agrotóxicos: Monsanto, Bayer, Syngenta, Dupont, Basf e Dow. "Essas seis empresas controlam a produção de sementes do mundo".

Figura 02: Foto de banca de feirante no Galpão da feira de Babaçulândia.

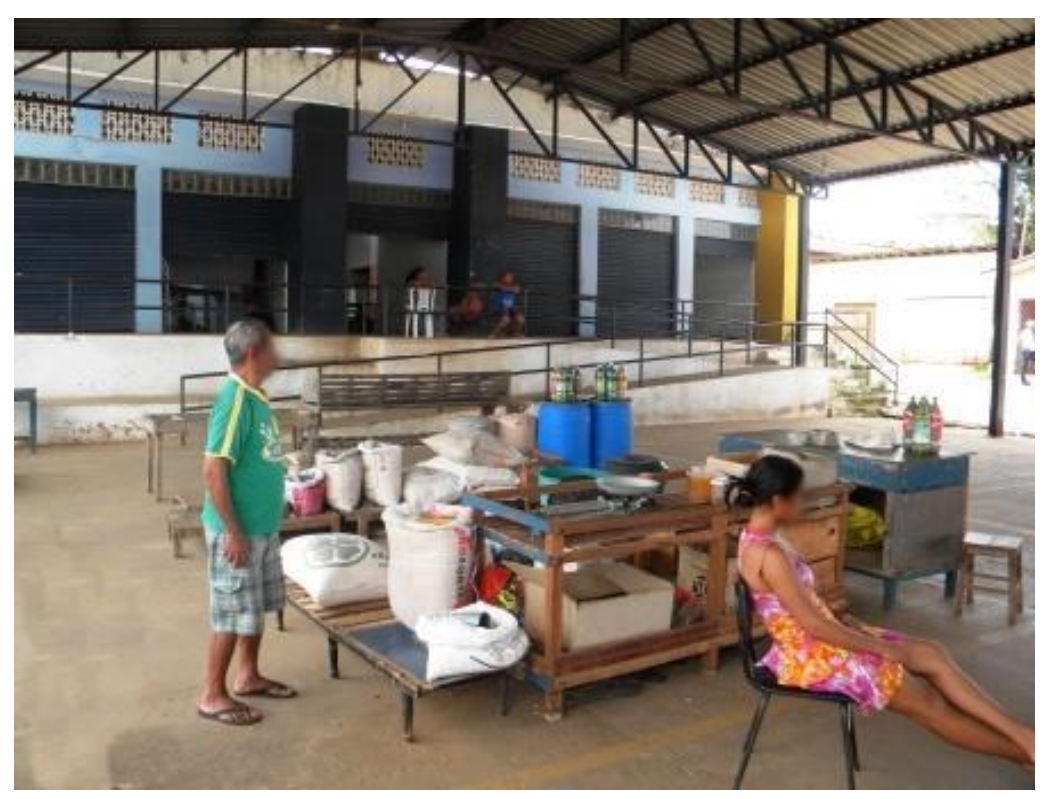

Foto: Eliseu Pereira de Brito, 2015.

Com a falta de adaptação na agriculta nas novas propriedades, muitos assentados estão desistindo, vendendo as suas e se mudando para as cidades. Araguaína tem recebido vários ex-assentados da terra que chegam com algum recurso financeiro e serve para inflacionar seu mercado imobiliário. O preço da terra varia nos assentamentos citados, mas custa, em média, treze mil reais $(\mathrm{R} \$ 13.000,00)$ o alqueire. E, como cada assentado recebeu oito alqueires, o preço estimado em cento e quatro mil reais $(\mathrm{R} \$ 104.000,00)$, valor de um lote em novos bairros criados em Araguaína. Várias dessas pessoas, ex-assentados, compraram lote a prestação e se endividaram junto ao sistema financeiro e grupos imobiliários para a construção das casas. 
Por serem trabalhadores rurais, tornam-se mão de obra desqualificada na cidade, pouco valorizada, servindo para equilibrar o valor das diárias e salários dos trabalhadores da construção civil, domésticos ou dos zeladores de fazenda e chácara. A maioria dessas pessoas mora nas periferias de cidades como Araguaína ou nas vilas das pequenas cidades das margens do rio Tocantins em uma tentativa de fazerem o retorno da interdependência com o rio Tocantins.

\section{CONSIDERAÇÕES FINAIS}

Entendemos que o trabalhar dos sujeitos ribeirinhos com o rio Tocantins e a lógica de acesso as feiras para negociar sua produção estabeleceu um maior apego com a terra. E, não foi apenas pelo trabalho, pois o ócio também para estes sujeitos foi importante na sua identificação com os lugares e território. A relação do trabalho tem sua importância porque os ribeirinhos são e se sentem como produtores de alimentos, função essencial para garantir sua sobrevivência (SACHS, 2002). O labor dos ribeirinhos, a importância do rio Tocantins e o avanço do agronegócio no Cerrado tocantinense nos instigaram a analisar estes sujeitos moradores das margens deste rio antes e depois do enchimento do lago da UHE Estreito. Para empreender tal análise, visitamos os assentamentos rurais e urbanos, e encontramos os sujeitos ribeirinhos buscando dar novo sentido à vida.

$\mathrm{Na}$ cidade, as feiras tornaram-se um lócus de nossa observação e não faltaram interrogações que, neste ensaio, buscamos responder a algumas como: a importância da produção agrícola para os mercados das cidades ribeirinhas. As feiras transformaram-se em galpões vazios ou contentam-se apenas com pequenos comerciantes que vendem produtos industrializados ou beneficiados. Não é mais o "litro" que mede o feijão ou o arroz, mas é a balança que pesa tudo, quando já não está na embalagem o peso.

A construção das hidrelétricas, apesar de uma política de reassentamento de parte dos atingidos, na zona rural, desmantelou a organização da vida econômica desta população, posto que era relacionada ao controle natural da fertilidade do solo pelo rio. Processo que modificou o papel de cidades-feiras como Babaçulândia na rede urbana.

É importante ressaltar que as ações do MAB nas periferias das cidades mostram para essa população as mazelas do setor energético e propõe ações de lutas junto a esta comunidade de atingidos. De fato, é um foco de resistência, pois ter ações nas cidades é uma forma de mobilizar um maior número de indivíduos para defender a bandeira de luta, mesmo 
quando as empresas se blindam com a construção de um quartel da Polícia Militar em frente ao seu escritório na cidade de Estreito-MA.

\section{REFERÊNCIAS}

ARAÚJO, Elisa Cotta de. Nas margens do São Francisco: sociodinâmicas ambientais, expropriação territorial e afirmação étnica do Quilombo da Lapinha e dos Vazanteiros do Pau de Légua. 2009. Dissertação (Mestrado em Desenvolvimento Social) Universidade Estadual de Montes Claros, Montes Claros - MG, 2009.

BONNEMAISON, Jöel. Viagem em torno do território. In: CORREA, Roberto Lobato; ROSENDAHL, Zeny. Geografia cultural: um século. Rio de Janeiro: EdUERJ, 2002. p. 83132.

Porter sur la nature un regard amical. Savoirs: une terre en renaissance: les semences du développement durable. Paris: Le Monde diplomatique, 1993. p. 55-56

Tanna. Les fondements géographiques d'une identité: les Gens des lieux. Histoire et géosymboles d'une société enracinée. Paris: Orstom, 1987.

BRITO, Eliseu Pereira de. O papel de Palmas na rede de integração regional. 2009. Dissertação (Mestrado em Geografia) - Curso de Programa de Pós-graduação em Geografia, FCH, Universidade Federal da Grande Dourados, Dourados, 2009.

CABRAL, Maria do Socorro Coelho. Caminhos do gado: conquista e ocupação do sul do Maranhão. São Luís: SIOGE, 1992.

CAMARGO, Beatriz e HASHIZUME, Maurício. Atingidos pelas obras de hidrelétrica enfrentam incertezas. Repórter Brasil. São Paulo, s/p., 31 de julho de 2012. Disponível em: http://reporterbrasil.org.br/2008/07/atingidos-pelas-obras-de-hidreletrica-enfrentamincertezas/. Acessado em: 02 de janeiro de 2014.

CONEXÃO TOCANTINS. Em Babaçulândia famílias assentadas pelo Ceste reclamam da falta de assistência. Conexão Tocantins. Palmas, TO, s/p., 19 de março de 2012. Disponível em: http://conexaoto.com.br/2012/03/19/em-babaculandia-familias-assentadas-pelo-cestereclamam-de-falta-de-assistencia. Acesso em: jan. 2014.

CAMPOS FILHO, Romualdo Pessoa. Um olhar geopolítico sobre a água no Cerrado: apontamentos para uma preocupação estratégica. In: PELÁ, Márcia; CASTILHO, Denis (orgs.). Cerrados: perspectivas e olhares. Goiânia: Editora Vieira, 2010. 
FOSCHIERA, Atamis Antonio. Da barranca do rio para a periferia dos centros urbanos: a trajetória do Movimento dos Atingidos por barragens face às politicas do setor elétrico no Brasil. 2009. Tese (Doutorado em Geografia) Universidade do Estado de São Paulo, Presidente Prudente, 2009.

GOMES, Horieste. A nova matriz espacial do território goiano. In: GOMES, Horieste. Universo do cerrado II. Goiânia: UCG, 2008. p. 353-376.

HAESBAERT, Rogério. O mito da desterritorialização: do "fim dos territórios" à multiterritorialidades. 6. ed., Rio de Janeiro: Bertrand Brasil, 2011.

IBGE. SIDRA. Dados Estatísticos de produção para o período de 2008 à 2012. Rio de Janeiro: IBGE, 2016. Disponível em: http://www.sidra.ibge.gov.br/. Acesso em: 10 de fev. 2016.

RODRIGUES, Rosana da Silva; BRITO, Eliseu Pereira de. Os ribeirinhos atingidos pela UHE Estreito-MA e sua nova territorialização no município de Babaçulândia -TO. In: XVII Encontro Nacional de Geógrafos, 2012, Belo Horizonte. Anais... UFMG, 2012. p. 01-10

SÁ, Rosangela Ferreira da Rocha e BRITO, Eliseu Pereira de. Redefinições territoriais a partir de um estudo de caso com ribeirinhos do município de Babaçulândia -TO. Caminhos de Geografia. Uberlândia: UFU, v. 13, n. 44, p. 01-12, dez/2012.

SACHS, Ignacy. O gato de Alice e outras crônicas: pensando o Brasil às margens do Sena. São Paulo: Cortez, 2002.

SANTOS, Boaventura de Sousa. Para uma sociologia das ausências e uma sociologia das emergências. Revista Crítica de Ciências Sociais. Portugal: Coimbra: Faculdade de Economia de Coimbra, p. 237-280, 2002.

SIEBEN, Airton. Estado e Política Energética: a desterritorialização da comunidade rural de Palmatuba em Babaçulândia (TO) pela Usina Hidrelétrica Estreito. 2012. Tese (Doutorado em Geografia) Universidade Federal de Uberlândia, Uberlândia, 2012.

SOUZA, Angela Fagna Gomes de. et al. O viver e o habitar: os ciclos da natureza e os usos dos territórios fluviais no rio São Francisco - Pirapora/MG. Caminhos de Geografia. Uberlândia: UFU, v. 11, n. 36, p. 01-10, 2010.

TRACTEBEL ENERGIA. Para mover o Brasil. Informativo da Tractebel Energia. Ano 8, N. 44, Outubro/dezembro 2012. p. 06. Disponível em: http://www.tractebelenergia.com.br/wps/wcm/connect/e4522a12-ccb3-4ba3-85b2068214f95444/BAIXA_tcb_tractebel_revista_boasnovas_5ed.pdf?MOD=AJPERES\&CACH 
EID=ROOTWORKSPACEe4522a12-ccb3-4ba3-85b2-068214f95444. Acesso em: 10 set. 2015.

\section{LISTA DAS ENTREVISTAS ${ }^{3}$ :}

Entrevista concedida pelo senhor Manuel na orla do Lago na cidade de Babaçulândia em setembro de 2016.

Entrevista concedida pela professora Rita na Universidade Federal do Tocantins em Araguaína em julho de 2012.

Entrevista concedida pelo senhor Sebastião no assentamento Baixão em Babaçulândia em março de 2013.

Entrevista concedida pela senhora Maria José no assentamento Baixão em Babaçulândia em março de 2013.

\footnotetext{
${ }^{3}$ Utilizamos apenas o primeiro nome.
} 